DOI: $\underline{\text { https://doi.org/10.34069/AI/2021.45.09.28 }}$

How to Cite:

Zakharova, L.F. (2021). Science organization of management as a method of production systems' effectiveness increasing. Amazonia Investiga, 10(45), 281-292. https://doi.org/10.34069/AI/2021.45.09.28

\title{
Science organization of management as a method of production systems' effectiveness increasing
}

\section{Научная организация управления как способ повышения эффективности производственных систем}

Received: March 1, 2021
Accepted: July 30, 2021

Written by:

Lilya F. Zakharova ${ }^{113}$

https://www.elibrary.ru/author_profile.asp?id=1067513

https://orcid.org/0000-0003-1834-8227

\begin{abstract}
Modern high-tech production must be highlyeffective and competitive, what is possible only when effective management system is available. There are disadvantages and problems of domestic machine-building enterprises and their practical experience. On the basis of made research with using fundamental theoretical and applied developments in the sphere of increasing management there is suggested conceptual appearance of a unique prognostic system of machine-building enterprises not mass production, the choice of directions of increasing these enterprises' operative management system is justified. The purpose of the article is to propose ways to improve the efficiency of manufacturing enterprises. The methodology used in conducting this study and developing proposals for increasing the efficiency of production systems is based on the principles and methods of the general theory of management, its cybernetic and social components, as well as methods of specific management sciences for the creation and effective functioning of enterprise management mechanisms.
\end{abstract}

Keywords: operative planning, predicting, production system, strategic management.

\begin{abstract}
Аннотация
Современное

высокотехнологичное производство должно быть высокоэффективным и конкурентоспособным, что возможно лишь при наличии эффективной системы управления. В работе рассматриваются недостатки и проблемы предприятий отечественного машиностроения, анализируется их практический опыт. На основании проведенных исследований с использованием фундаментальных теоретических и прикладных разработок в области совершенствования управления предлагается концептуальный облик единой прогностической системы машиностроительных предприятий не массового типа производства, обосновывается выбор направлений совершенствования системы оперативного управления этими предприятиями. Цель статьи - предложить пути повышения эффективности производственных предприятий. Методология, использованная при проведении данного исследования и выработке предложений по повышению эффективности производственных систем, базируется на принципах и методах общей теории управления, её кибернетических и социальных составляющих, а также методах конкретных управленческих наук по созданию и эффективному функционированию механизмов управления предприятиями.
\end{abstract}

Ключевые слова: оперативное планирование, прогнозирование, производственная система, стратегическое управление.

\footnotetext{
${ }^{113} \mathrm{PhD}$ in Economic Sciences, Associate Professor, Moscow Aviation Institute (National Research University), Moscow, Russia.
} 


\section{Introduction}

In modern world, which is characterized as a time without regularities eclectic is becoming common thing: there is combining of values and concepts. Objective terms of return to human values became a threat of humanity living on Earth, which appears in different spheres and letting us know about it more and more often. History teaches that the base of wealth is material production. Separation from the real base of existing can turn into the loss of country's strategic safety that is why a known tendency of outputting a number of productions from USA in terms of outsourcing in developed countries nowadays changes in diametrically opposite direction. For domestic enterprises modern stage of development is neo industrialization. In macroeconomic scales the solution of the productionally-technological base of domestic machine-building modernization task is potentially provided by all necessary for these resources, in contrast with the before more adverse development periods. However, as the practice shows, domestic production gives up its positions in comparison to the last period, more and more stepping back from the developed countries (Barinov, \& Okatiev, 2017; Bratukhin, 2014). Force majeure with coronavirus pandemic can make this process catastrophic with other same terms.

Modern production in whole and hightechnological industry in particular has a specialty, which really makes these objects' management processes harder: wide nomenclature, scientifically-technical and technological intensity, high labor input, long production cycle of made production creation, its common changing and constructivelytechnological completions and special demands to the quality (Knyazev, 2016). Enterprises of domestic machine-building where serial production type is higher, which in organizational plan is rather harder in comparison to mass one, nowadays face the following problems, which make their production uncompetitive on the world markets: not enough attention to scientifically-technical production preparation, inconsistency to production-technological base of modern production demands (old technologies, morally and physically worn out of equipment) and low effectiveness of management systems.

The key to further prosperity and development of domestic production, its final result, is a highlytechnological, scientific and highlytechnological strategically competitive on world markets production. Making the modern production objects harder is not only reality, but also imperative of modern world. In new technics there are formed the ideas of its best performers, whose art labour can be estimated only by equal to them minds. Machine-building digitalization, implementation of industrial standards automation Enterprise Resource Planning (ERP), Material Resource Planning (MRP), Manufacturing Execution System (MES) (PJSC NPO Saturn, JSC Russian Helicopters, etc.) are "steps" towards creating "smart (non-human)" plants with high degree of production and managements processes automation (Zagidullin, 2011; Polyanskov et al., 2014; Solomentsev \& Frolov, 2015). For increasing effectiveness there are the most easy tools of information flows automation: systems of electrical documents integration (EDI) and different by scientific capacity information technologies (Data Mining), in which on the basis of reported and forecasted data intellectual analysis there is generated information for accepting hard management decisions (Zakharova et al., 2017; Porter, 2017).

The disadvantages of realized by enterprises projects of management systems' automation are: absence of complete strategic picture and projects' systematization, patchwork of their adoption, conceptually-instrumental inconsistencies of different program products among themselves, inconsistency of given results because of low reliability and doubling of information providing and high cost. As a result there is low effectiveness of given to the digitalization of financial costs (Sadovnikova \& Shmoilova, 2016; Medvedeva, Museridze \& Frolov, 2012).

The main factor of increasing production systems' effectiveness is scientific approach to organization of their management system (Zakharova \& Novikov, 2012; Semenov, 2019).

In this article there is suggested a full production systems' management system, based on the complex forecast of strategic and operativelytactical changes, formation on the basis of forecasts of set plan decisions and operative tasks for its support (Zakharova \& Novikov, 2016; Zakharova \& Novikov, 2016).

\section{Literature Review}

Modern literature is replete with works in the field of improving the efficiency of management 


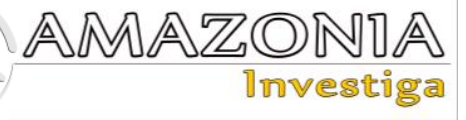

and management of production systems of enterprises. At the same time, on the one hand, it is possible to single out the authors substantiating the point of view about the deep crisis of modern management. For example, Doctor of Economics, Professor A.V. Busygin (2015) is puzzled not only by the stagnation of Russian industry, but also by the lack of achievements in the field of modern economic theory. He speaks directly in the publication of the same name about the crisis of modern management.

The overwhelming majority of other researchers offer a lot of specific ways to solve scientific and practical problems in various areas of modern theory and practice of management, including in the field of production management, starting from its fundamental foundations. These include, for example, Barinov V. A., \& Okatiev N. A. (2017), Bratukhin A. G. (2014), Knyazev E. N. (2016), Medvedeva G. M., Museridze A. B., \& Frolov E. B. (2012), Polyanskov Yu. V., Totorkov A. M., Frolov E. B., Gismerylin A. R., Zaykin M. A., \& Lototsky A. M. (2014), etc.

The methodology and tools of lean manufacturing, as well as logistic integrated management systems based on CALS technologies and standards for automation of production process control - MES-systems, presented in the works of Russian and foreign authors such as Bratukhin A. G. (2014), Porter M. (2017), Sadovnikova N. A. and Shmoilova R. A. (2016), Semenov S. S. (2015), etc. However, today there is no complete picture of the way out of the crisis of Russian industries, covering all aspects of their activities and subordinate single goal.

The author of this article, having many years of experience in scientific and practical and pedagogical activities in the field of management, came to the conclusions and proposals presented both in this work and in other publications, including monographs (Zakharova \& Novikov, 2012; Zakharova \& Novikov, 2016a; Zakharova \& Novikov, 2016b; Zakharova et al., 2017).

\section{Methodology}

The theoretical basis of the proposed work is cybernetics, control theory, theory of complex systems, forecasting, theory of fuzzy sets and the main categories are such concepts as forecasting, strategic, tactical and operational management, large organizational and economic production systems, considered in fundamental and applied works (Zakharova et al., 2017; Medvedeva et al.,
2012; Sadovnikova, \& Shmoilova, 2016). The methods used in writing the work are scientific tools of the general theory of management and its functional subsystems: forecasting, production tactical planning, operational production management, as well as the empirical method used in the study of the activities of a number of the largest enterprises in mechanical engineering. The prerequisites for writing the work are the problems identified by the author in the practice of managing modern manufacturing enterprises, including aerospace, and the solutions proposed by the author, presented by him in articles, monographs, educational and scientific publications, as well as postgraduate dissertations written under his leadership.

\section{Results and Discussion}

In accordance with Ashby's (1959) cybernetic law of necessary diversity, the control system must correspond in its complexity and quality, at least not be inferior to the complexity of the controlled object. In other way it is not effective, because the managed object will not reach the given goals. Thus, the most actual task is reorganization of management systems with the usage of saved in this sphere practical experience and theoretical knowledge. If we rely on the theory of modern management, analysis of its fundamental resources shows that management science is in crisis situation. Well-known historical schools of management theory, while basing on different periods key factors of success, starting from the meaning of the management activity on its own and systematization of management functions, including mathematical and behavior schools and achieve continuing in different proposed conceptions (situational, process management, concept of global strategy, etc.), which, on the one hand do not bring new knowledge in this sphere, but on the other hand do not give clear answers on practice's question. Informationallymethodological domestic enterprises management base is full of variety, not systematization and not effectiveness because of:

- firstly, possible misunderstanding of management nature;

- secondly, absence of strategic topmanagement, effective high guide, effective owners of business and government structures;

- thirdly, blind copying of western models of management innovations.

Modern business, while failing under the work of outer world factors, had to turn to strategic 
planning theory, which usage was a successful experience and had long-century history in the sphere warfare and government management, starting with the time of Ancient Greece and before it. Scenario-strategic planning in terms of unstable environment replaced long-term extrapolation planning, having come through quality changes in contents and technologies, but staying planning on perspective itself. Understanding the role of strategic planning, government structures develop strategic programs and economic development projects and its separate spheres. There was accepted the law "On strategic planning in the Russian Federation" No.177-FZ. Its role in managing large-scale scientific business is exceptional in its importance. However, the narrowness of planning horizon of strategic planning, mentioned in the law, does not accord to temporary parameters of life cycle of not only national economy, but also its separate enterprises, and consequently to the concept "strategic" one. The existing position of domestic production complex is due to the lack of scientific organization of production management and, firstly, really working mechanism of strategic planning.

The defining and leading category in strategic management is the concept of goal. Goals for organizationally-economic systems are not only specific ending positions and results of their activity, which are the base for building criteria of their estimation, but also subjective reflection of objective reality, showing interests of enterprise owners, staff and society, which are the motives and incentives of people's behavior in their joint labor activity. In critical periods of development the most important are goals, classified by stages of management object's life cycle:

- goals of system's creation (defining the necessity in product, system's projecting and access to the market);

- goals of stabilization (providing normal income of business, image creation, keeping or small expanding of the owned part of the market's share and development of rational tactical movements, while saving the basic strategy);

- goals of system's development (increasing the income, quantity and quality indicators' growth, new products' production and access to new markets).

The main common strategic goal of production system as organizationally-economic system is mission. The concept of strategy for organizationally-economic systems, consequently must come from and base on the meaning of the concept "mission". Considering missionary goal of business, there can be made a conclusion about its highly-humanistic role, but its merit is connecting of war terminology strategic management technology with human, universal concept "mission". For conquering worthy strategic niches in geopolitical sphere it is necessary to have clear understanding of the mission and goals of every participant of triad (Figure 1).

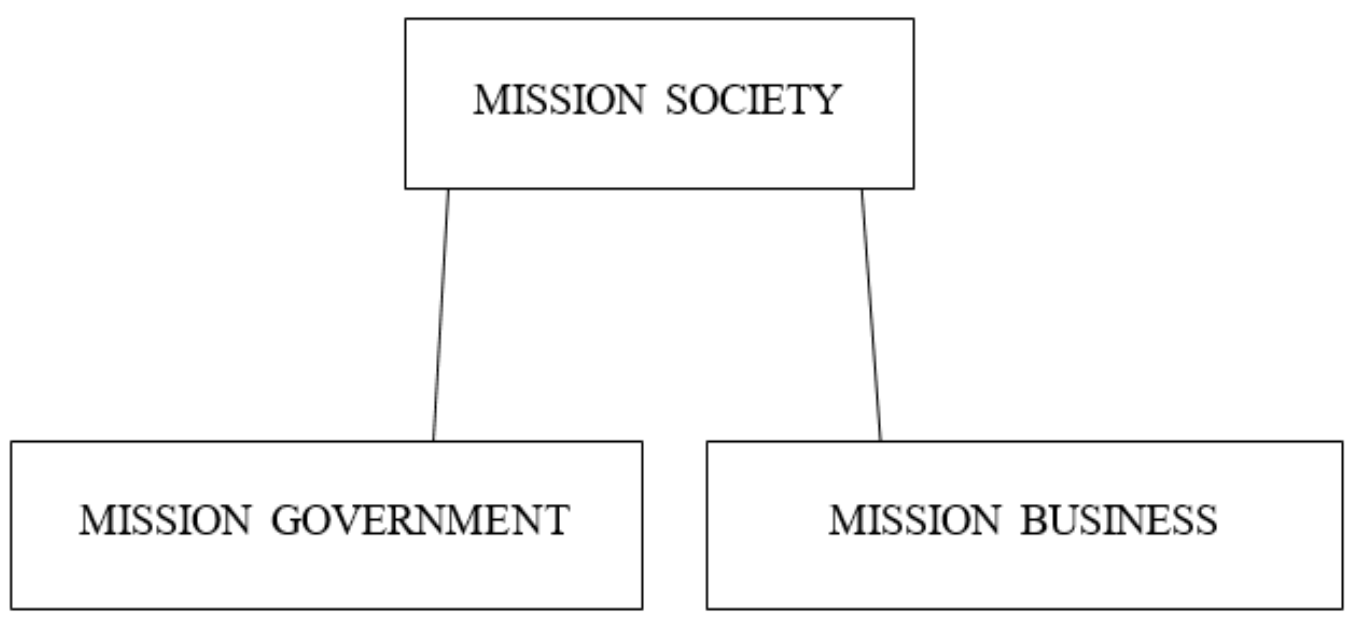

Figure 1. Main participants of strategic cooperation.

This cooperation is impossible without agreeing and defining subordination of the goals, including such global ones as missionary destination. Here missionary destinations of business and government have subordination character towards the society mission. The society in face of public institutes dictates and realizes universal values and rules. Government 


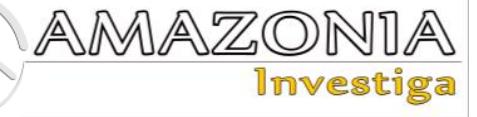

sets formal rules for its all members. Business destination is receiving of additional cost for providing further development of all triad as a whole system. The balance of interests is possible only with availability of realized, but not formally set missions of every participant.

Scientific systematization of management activity spheres points out prognosis function as its starting beginning stage. Dynamic of scientifically-technological progress, intensity of competition, unpredictability of consumers preferences and connected with these factors high uncertainty and unpredictability of tomorrow events make prognostic one of the most demanded spheres of science, but from the other point increase demands to trustworthiness and accuracy of the prognosis. The prognosis is prelude of any plan, and the last controls all further movements of manager. Domestic school of prognosis was high: developed by it prognosis tool was successfully used for solving tasks of creation scientifically-technical, sociallyeconomical and other prognoses on the level of separate spheres and national economy in whole. However, in terms of directional centralized management separate enterprises and communities have never been independent objects and subjects of prognosis. With a transfer to the market, the situation has sharply changed in the necessity in results sphere at first tactical, and then strategic and operational prediction. However, even nowadays there is a big separation between macro prediction and micro prediction, which is a level of separate enterprises and units. This connects with the structure of the prediction apparat on its own, its place and roles in enterprises' activity, prediction tool on all temporary horizons of prediction: perspective strategic, middle term, short-term and operational.
In the prediction sphere on domestic enterprises there can be pointed out the following problems:

- lack of intrumentional-methodological prediction providing;

- imperfection of special necessary knowledge and experience of creation scientifically-proved strategic and realistic operational predictions;

- imperfection and non-systematization of informational basis;

- lack of organizational providing;

- crudity of terms and default level of prediction;

- varieties of existing programmedmethodological providing, input intensity of its buying and adaptation (for tactical predictions).

The work of various authors is devoted to the problems of forecasting in the activities of an enterprise in market conditions. However, the solutions proposed in them, considering in detail certain areas of the enterprise's activity, do not give an idea of an integral forecasting system. The publications in this area, also, as a rule, do not stipulate the time horizons of forecasting, without presenting the forecasting activity of the enterprise as a complex of interrelated forecasts.

For making system prediction activity on enterprises it is necessary to firstly point out elements of such system. In our view, the structural elements of prediction system of the enterprise must be the following ones (Figure 2):

- perspective prediction for $10-15$ and more years;

- middle term prediction for 3-5 years;

- $\quad$ short-term prediction for a 1 year;

- operational prediction from a quarter to shift and hour. 


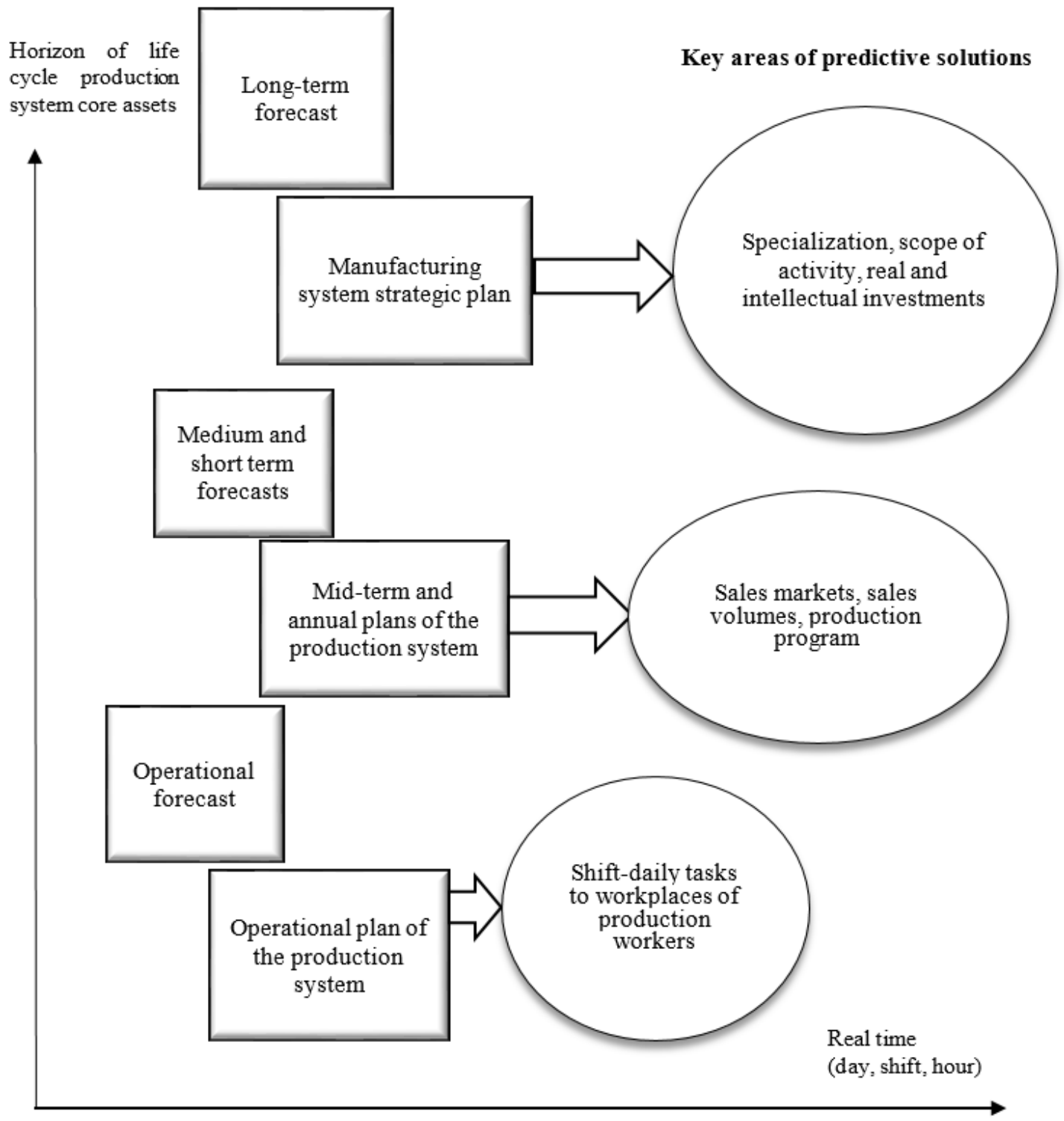

Figure 2. Horizons and key areas of production system prediction decisions.

A problem of particular importance in the conditions of modern neo-industrialization is the design of the forecasting system for industrial enterprises of single and serial production.
The proposed conceptual appearance of the forecasting system of an industrial enterprise of a non-mass production type for the main key areas of forecasting is shown in the Figure 3. 


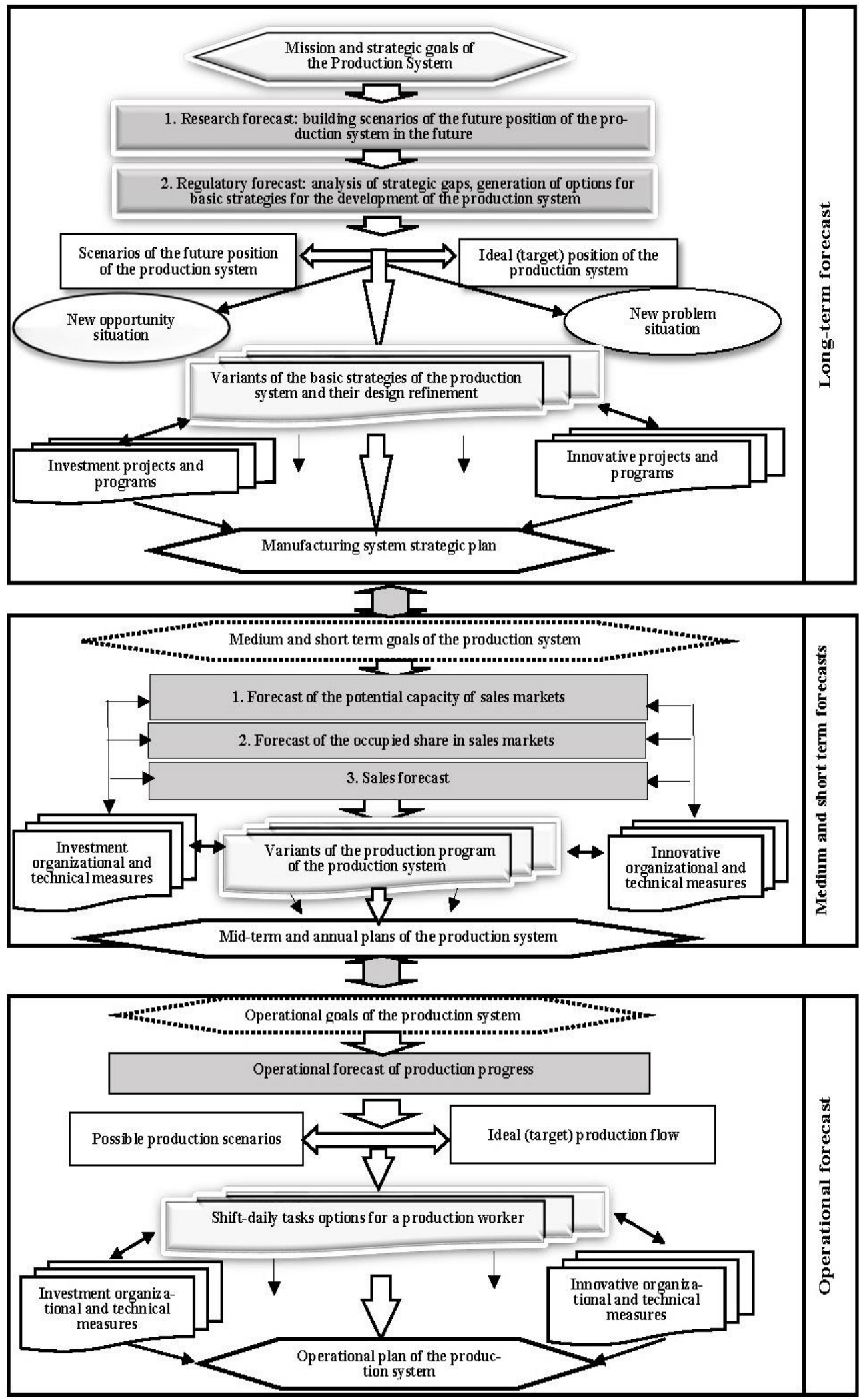

Figure 3. Conceptual appearance of the forecasting system of a manufacturing enterprise in key areas of forecasting.

Methodological hardships of development and implementation of enterprise's prediction system come from the character of the solved problems.
Perspective strategic (unlike long-term (differences between strategic and long-term prediction are not only in the horizon of 
prediction: both are perspective, i.e. made for a period of $10-15$ or more years, but in used methods and formation mechanisms)), such as operational interactive prediction, rely to the class of weakly-structured, but more often nonstructural tasks are the least formalized part of the enterprise's prediction system. This is connected with high definition of prediction context, uncertainty of managing object goals, criteria (for strategic horizon) and ways of reaching goals, necessary for these resources. In strategic relation this, first of all, relies to the task of choosing investment enterprise's attachments perspective directions, stating choice of the competitive breakthrough scientificallytechnical products and scales of its production in world-wide markets.

On the level of operational prediction there are the questions of making shift-daily tasks by worker of parts of production enterprises' shops. In terms of strategic prediction the problem is choice of prediction tool, which would be rather effective for solving the given tasks on the level of separate enterprises. Without considering in this work such tool of strategic prediction, we only point out that for perspective prediction of production systems development there is essential usage of system analysis methods, such as economically-mathematical and statistical modeling with the accent on expert heuristic methods. Matrix models, suggested by western management, are simplified systematization strategic information form and can be used for solving strict tasks circle, such as leading strategic information to corporative owners in terms of sprayed property form (American model for corporative management).

One of the most problematic questions is also the choice of estimation criteria of the whole enterprise's place in perspective. In our point of view, the main indicators, showing the perspective place of production enterprise of high-tech scientific production industries, must be not profit and profitability of production, but indicator of strategic competitiveness of made production per unit of cost. This will allow avoiding short-term "fast" investments, profitable in receiving feedback in short-term perspective, which slow down researches, developments and production of hard scientific competitiveness on world-wide production markets.

In order to realize strategies, it is necessary to take serious actions on the chosen route, make tactical and operational management, whose essence of which is concreting and detailing in space and time of developed strategies. The cycle of managing functions in this repeats, but on less management horizons. The ending detailing of activities finds embodiment in operational planning. Operational and tactical movements are pointless, if there is not given perspective direction of movement, which are strategies.

The main task of middle cost tactical prediction for 5 years must be the task of predicting the selling volumes on each sales market. This task must be solved step by step:

- $\quad$ on the first stage there is prediction of potential capacity of each markets' segment;

- on the second stage there is made comparative competitive analysis and really possible sales in middle term perspective are estimated.

On the basis of middle term prediction there is formed a production enterprise's program.

The hardest one in prediction system is operational prediction, together with perspective one, which specialty consists in high degree of situation's non-definition after the variety and force majeure character of possible confusing factors, which work with making operational decisions, and also in the lack of temporary lag among prediction, making decision and it's factual completing. Effective system of operational production management, its vertical and horizontal integration with all subsystems of enterprise's management in operational reaction on changes of inner and outer spheres is a key to successful completing of strategic settings and success of the enterprise in whole. The base for increasing machine-building production operational management are logistic integration systems of operational management, combining concepts of system process approach, "saving" production, Continuous Acquisition and Life Cycle Support (CALS) technologies Bratukhin, 2014, budgeting, controlling and based on using of counting technics. This includes "pulling out" and corporation information systems, based on foreign production management standards. The first place on such enterprises is given to the idea of creating maximally balanced technological process with high intensity and maximum flexibility of working powers and equipment.

In terms of implementation of "Smart Factory" projects on machine-building enterprises in Russia nowadays there is automation and robotization of production parts and flexible production-logistic systems, which include 


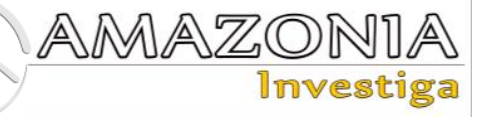

automation of the operational level management processes. However, on most enterprises of machine-building complex without automation there is still formation of shift-daily tasks and creation of essential for this prediction information database. Shift-daily planning is an ending stage of production planning, strictly connected with production way operational regulation, which is made in real time on the level of separate worker and workplace, taking into consideration forming conditions (possible breaks of equipment, delays in supplying raw materials, preparations, semifinished products, details, completing products, tool and fixtures, unplanned tasks, not showings of production workers, etc.). With operational management system functioning in real time it is necessary to make a proactive prediction of appearing possible disagreements and form optimal planned tasks for executors. As a result of adaptation hardness and high cost of programmed products its creation on most enterprises is not automatized and made by hands. Available in this sphere programs are based on using hard mathematical instrument, which allows maximally clear and adequate consider the given parameters and their change in operational production planning. These are models of optimization, immigration models, heuristic and models of mathematical statistics. Wide usage has models of optimization, which consist of linear and nonlinear programming, dynamic programming, network planning, etc. Modern programmed provision allows receiving variants of shift-daily tasks, maximally close to optimal one. However, in sharp financial deficit expensive programmed products for solving tasks of forming shift- daily tasks, using highly clear mathematical tool mostly unavailable for domestic enterprises. In these terms the best variant, in our view, is using a mathematical tool, which is based on the unclear logic principal (logic of unclear output), programmed packet realization of which will be a compromise between very expensive intellectual systems of operational management and existing practice of forming production plan on the lowest level of "hand" management, this is especially actual for unstable production.

The principal of unclear logic is concluded in the possibility of making decisions in certain range of truth (Zakharova \& Novikov, 2016). In addition, instead of binary Boolean system of choice there is used the possibility of choice from 0 to 1 . The concept of "unclear variety" replaces characteristic function with membership function, which can have any meaning on the interval $[0,1]$ for $x \in A$. According to this element xi of variety $\mathrm{U}$ cannot belong to $\mathrm{A}(\mu \mathrm{A}$ $=0)$, can be element $\mathrm{A}$ in small degree $(\mu \mathrm{A}$ is close to zero), can more or less belong to $\mathrm{A}$ ( $\mu \mathrm{A}$ is not too close to 0 and to 1 ), can significantly be element $\mathrm{A}$ ( $\mu \mathrm{A}$ is close to 1 ) or can be element $A(\mu A=1)$. Variety of meaning of $x$, on which there is defined membership function, is called unclear variety.

Formation of shift-daily tasks is one of the possible spheres of practical usage of unclear conclusion logic, because it is connected with highly non-defined of outer and inter-system disturbances. While forming shift-daily plan the sector's planner cannot just set the degree of preference of one variant above another, but even clearly compare alternatives and forms a plan only with some level of confidence. Lack of operational prediction of disturbing factors causes deviations during production, whose intensity repeatedly increases for units (sections, workshops) with unstable production, which are characterized by the absence of strict fixing of the ciphers of the names of parts for the site, a sharp change in the volumes of their manufacture from period to period, the impossibility of determining in advance a month in advance the order of their launch and release at each workplace, which is most typical for the conditions of one-off production, but also typical for mass production, which is predominant in mechanical engineering, especially in high-tech business. Correction of shift-daily plan is made for later terms of making before planned nomenclature positions, which delaying planned buildings creation, brings chaotic in staff work, making intensity and conflicts on work places and in the end brings to disruption of planned tasks completion terms. In concepts of unclear logic formation of shift-daily task is a task with unclear logical derivation, making unclear conclusions on the basis of unclear conditions and premises. Fixation of concrete meanings from the interval $[0,1]$, which estimate degree of ownership of the plan alternatives, has subjective character. Building of ownership function is made using experts estimations and is defined by experience, intuition and other subjective factors of the one, who makes a decision.

The staged option for choosing preferred shiftdaily tasks alternatives can be formulated as follows. Let the following condition be presented to the set of all alternatives of the shift-daily task, formed taking into account probable perturbations:

$$
0,01<\mathcal{E}<0,15 \text {, }
$$


where $(\mathcal{E})$ is an unclear variable deviation from firstly set up (ideal) plan. Unclear variable is defined by its name, scope and description of restrictions on possible meanings. On received unclear majority of possible shift-daily tasks alternatives, there must be chosen some acceptable or one variant. While solving practical tasks, using unclear variety theory the most used were the easiest private cases of unclear numbers and intervals, which have received their name by the view of the ownership functions, which are linear one: triangle (for single variant) or trapezoidal (for range of possible options).

We suppose that for unstable production terms there are the following restrictions for possible deviations from ideal, formed on the stage of calendar planning, shift-daily tasks:
1. alternative of plan with deviations on the interval: $0<\mathcal{E}<0,01$ are estimated as ideal, but unlikely ones;

2. deviations on the interval: $0,01<\mathcal{E}<$ 0,05 are estimated as unideal, but possible ones;deviations on the interval: $0,05<$ $\mathcal{E}<0,10$ are estimated as not good enough, but appropriate ones;

3. deviations on the interval: $0,10<\mathcal{E}<$ 0,15 are estimated as satisfying;

4. deviation of indicators, which are higher than $\varepsilon \geq 0,15$ are estimated as inappropriate.

Then the function, according to these statements (in concepts of unclear logic is an ownership function) will have a trapezoidal view (Figure 4).

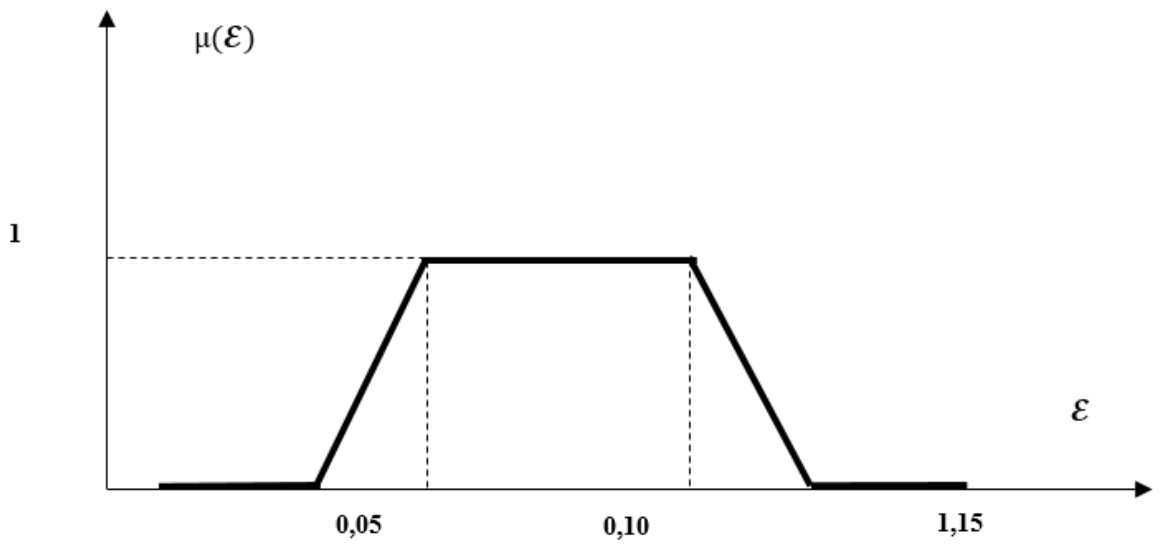

Figure 4. Ownership function $\mu$ of unclear variable $\mathcal{E}$

With using ownership function the trustworthy of statement $\mu(\mathcal{E})$ regarding to possible shift-daily tasks alternatives will be formally described by the following equation (2).

$$
\mu(\mathcal{E})=\left\{\begin{array}{c}
=\mathbf{0} \text { with } 0 \leq \mathcal{E}<0,01 ; \\
=\frac{1}{0,05-0,01} *(\mathcal{E}-0,05)=(\mathbf{2 5} \mathcal{E}-\mathbf{1}, \mathbf{2 5}) ; \\
=\mathbf{1} \text { with } 0,01 \leq \mathcal{E} \leq 0,05 ; \\
=\frac{1}{0,15-0,10} *(\mathcal{E}-0,15)=(\mathbf{2 0} \mathcal{E}-\mathbf{3}) ; \\
\text { with } 0,10 \leq \mathcal{E} \leq 0.15 ; \\
=\mathbf{0} \text { with } \mathcal{E} \geq 0,15 .
\end{array}\right.
$$

Unacceptable deviations from the performance indicators of the plan, as well as permissible, but very insignificant in conditions of unsteady production, are estimated with zero reliability, all other values will be acceptable and evaluated in a single standardized quantitative rating scale. 


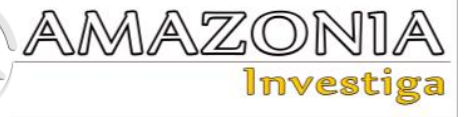

This method, realized in programmed packet variant, significantly easing shift-daily tasks formation process, reduces time for its development, will increase the state degree of production buildings on the direct performers level (production workers) will increase the management production cultural level.

The main differential specialty of this approach is that it shows real process, allows taking into consideration the impact of non-strict big number of hardly realized factors in forming shif-daily plans, which impact on flowing and the result of its completing and is comfortable when usage of hard mathematical models is difficult and costly.

Automated systems of operational management system, built on the unclear logic principal, are the most effective for the terms of unstable production. Practical usage of unclear logic tools on the one hand will not demand any significant investments, but on the other hand will increase the effectiveness of management by:

- providing the continuity (flow) of the processes of operational production management in real time;

- providing the complexity of operational management is the integration of management functions for short-term forecasting, operational-production planning, organization of production and dispatching of production processes;

- changes in the role of man in the humanmachine system as a result of the introduction and use of workstations of masters and planners of production sites.

Technology of applying the method of expert assessment in the formation of a shift-daily plan using the theory of fuzzy sets with operational forecasting requires the creation of an adequate retrospective information base.

\section{Results and Discussion}

The paper substantiates the need to develop a prognostic system of enterprises based on a systemic complex forecast, presents its conceptual and methodological appearance and possible tools for solving particular problems of operational management for machine-building enterprises of single and serial types of production.

The success of the practical implementation of the proposed solutions requires the creation of a single centralized databank for information and expert support at all horizons and levels of management. At the same time, the design of an expert support system should be considered as an iterative and evolutionary process, since the database should be continuously replenished and updated in the course of gaining experience in the process of its operation.

The presented proposals for improving production management, based on a comprehensive forecast, are necessity for the effective functioning of production systems, ensuring their strategic competitiveness in world markets, in particular this applies to high-tech science-intensive industries of mechanical engineering, where single and batch types of production prevail.

Discussions of the proposed solutions were carried out in scientific circles when publishing author's works, as well as among practitioners of Russian aircraft manufacturing enterprises and corporations. Since the improvement of enterprise management systems should be carried out taking into account the specifics of the conditions of their functioning, the issues of filling with the specifics of the proposed components of the forecasting system of enterprises should be considered and resolved in the process of developing and implementing relevant projects and programs for the development of Russian engineering enterprises.

\section{Conclusions}

Based on the above, the following conclusions can be drawn:

- Hardness of strategic prediction mechanism on a separate enterprise level needs a together participation in its development of intersectoral and government structures. On the government level, this activity sphere develops, gets embodiment in government target projects and programs, but still has not become an active tool on microeconomic level.

- Nowadays there is no clear understanding of perspective goals and strategies of production systems' development or temporary frames of enterprise's strategic plans development.

- Innovatively investment activity, including production enterprises automation questions has non-system character.

- Innovations in production sphere are separated from innovations in management sphere.

- There are absent qualified specialists, which do not accord to modern requirements of 
highly-technological hard production systems' management.

- There is not paid needed attention to main producer: workshops and parts of the main production, in addition to operational management system.

Reorganization of the existing production management systems has to be made on the following main principals:

- $\quad$ strict subordination to perspective strategic development plan of management object of production system;

- complex system connection with restructuration of production technical base of production system, but not the replacement of management processes by production ones;

- realization of strategic projects of improving management systems and organizational reengineering through tactical and operational events (kaizen).

- adequacy of organizational support to made changes.

The improvement of production management is proposed to begin with the design of the forecasting system of enterprises, based on scientific principles and management tools, taking into account the specifics of the industries under consideration.

\section{Bibliographic references}

Ashby, U. R. (1959). Introduction to cybernetics. Moscow: Ripol Classic.

Barinov, V. A., \& Okatiev, N. A. (2017). Strategy for restoring the competitiveness of the domestic rocket and space industry. Monograph. Moscow: RIOR: INFRA-M.

Bratukhin, A. G. (2014). CALS-technologies in the life cycle of Russian competitive civil aircraft. Monograph in 2 books. Moscow: MAI-Print.

Busygin, A. V. (2015). Management crisis. Essays on modern theory and current practice. 2nd edition. Moscow: Prospect.

Kanashchenkov, A.I., Novikov, S.V., \& Veas Iniesta, D.S. (2019). Technology formation of the mission of micro-level management enterprise in aviation. IOP Conference Series: Materials Science and Engineering, Volume 537, Issue 4. Doi: 10.1088/1757-899X/537/4/042040

Knyazev, E. N. (2016). Innovative complexity. Saint Petersburg: Aletheya.

Kofman, A. (1982). Introduction to the theory of fuzzy sets. Moscow: Radio and communications
Medvedeva, G. M., Museridze, A. B., \& Frolov, E. (2012). How to avoid mistakes when choosing a control system for machine-building production. Machine park, 8(96), 29-35.

Pinkovetskaia, I., Kryukova, L., Arbeláez, D., \& Rojas-Bahamon, M. (2019). Female Entrepreneurship: Types of Economic. Activity. Journal of history culture and art research, $8(2), \quad 253-265$. DOI:10.7596/taksad.v8i2.2153

Polyanskov, Yu. V., Totorkov, A. M., Frolov, E. B., Gismerylin, A. R., Zaykin, M. A., \& Lototsky, A. M. (2014). Evaluation of the possibility of applying the operational management system for production of the MES class within the framework of mechanical frame production of an aircraft building enterprise. Bulletin of MGTU Stankin, 3(30), 83-88.

Porter, M. (2017). Competitive advantage or how to achieve a high result and ensure its stability. Moscow: Alpina Publisher.

Sadovnikova, N. A., \& Shmoilova, R. A. (2016). Time Series Analysis and Forecasting. Moscow: Moscow Financial and Industrial University "Synergy".

Sadovsky, V. N. (1974). Foundations of the general theory of systems: logical and methodological analysis. Moscow: Science.

Semenov, S. S. (2015). Assessment of the quality and technical level of complex systems: practice of applying expert assessments. Moscow: Lenand.

Solomentsev, Yu. M., \& Frolov, E. B. (2015). Modern methods of increasing the efficiency of machine-building industries. Engineering Technology, 8, 54-58.

Zagidullin, R. R. (2011). Management of machinebuilding production using MES, APS and ERP systems. Monograph. Stary Oskol: TNT.

Zakharova, L. F., \& Novikov, S. V. (2012). Strategic changes in large-scale organizational and economic systems: justification and implementation. Proceedings of the Moscow Aviation Institute, 53.

Zakharova, L. F., \& Novikov, S. V. (2016a). Formation of the organizational and executive poly-structure for the implementation of science-intensive projects. Models, Systems, Networks in Economics, Technology, Nature and Society, 3(43), 52.

Zakharova, L. F., \& Novikov, S. V. (2016b). Management of competitive selection of hightech scientific and technical projects. Monograph. Moscow: MAI Publishing House.

Zakharova, L. F., Kudryavtsev, S. M., \& Novikov, S. V. (2017). The implementation of a systematic approach to solving the problem of integration of participants in large-scale scientific and technical competitive projects. Bulletin of the Moscow Aviation Institute, 24(1), 180-191. 